\title{
AS PESQUISAS EM CRENÇAS NO ENSINO- APRENDIZAGEM DE JAPONÊS COMO LE NO BRASIL
}

Yûki Mukai ${ }^{1}$

Resumo: Este estudo tem como objetivo investigar e discutir o estado da arte sobre as pesquisas em crenças no ensino-aprendizagem de japonês como língua estrangeira (JLE) no Brasil, com enfoque em suas questões metodológicas. Para isso, foram compilados os trabalhos publicados e/ou realizados nessa área até o presente momento (novembro de 2015) e, em seguida, foi feita uma meta-análise qualitativa, estabelecendo seis categorias de análise, a saber: (1) modalidade de publicação, (2) autores/ano de publicação/instituição, (3) foco da pesquisa, (4) participantes da pesquisa, (5) método/natureza de pesquisa e (6) instrumentos de coleta de dados. Os resultados mostraram que a maioria das pesquisas em questão aborda crenças de alunos, utilizando o método qualitativo com a natureza de um estudo de caso interpretativo. Diante desse estado da arte, pode-se afirmar que serão igualmente importantes investigações sobre crenças de professores e de terceiros, pesquisas configuradas como uma pesquisa-ação ou um estudo de caso interventivo, bem como pesquisas com a abordagem quantitativa.

Palavras-chave: Pesquisas em crenças. Contexto brasileiro. Ensino-aprendizagem de japonês como língua estrangeira. Meta-análise qualitativa.

Abstract: The aim of this study is to investigate and discuss the state of the art of the research
about beliefs on the teaching-learning of Japanese as a foreign language (JFL) in Brazil,
especially focusing on its methodological matters. For this purpose, the researches published
and/or realized in that field up to the present moment (November 2015) were collected and
afterwards a qualitative meta-analysis was made by establishing six categories of analysis: (1)
sort of publication, (2) authors/year of publication/institution, (3) focus of the research, (4)
participants of the research, (5) method/nature of the research and (6) data collection instruments.
The results have shown that most of the mentioned studies deals with students' beliefs, and uses
the qualitative method with an interpretive case study approach. Taking this state of the art into
consideration, it can be concluded that research on beliefs of teachers and third agents, an action
research or intervention case study approach, as well as research with a quantitative approach

1. Professor Adjunto do Curso de Letras-Japonês da Universidade de Brasília (UnB).prof.yuki@gmail.com 
will be equally important.

Keywords: Research on beliefs. Brazilian context. Teaching-learning of Japanese as a foreign language. Qualitative meta-analysis.

\section{Introdução}

O estudo sobre crenças no ensino-aprendizagem de línguas tem se tornado um dos campos de investigação fértil na Linguística Aplicada brasileira e, de fato, o número de artigos publicados a respeito do tema tem crescido consideravelmente (BARCELOS, 2001; 2003; 2004, p. 124; 2007, p. 27; SILVA, 2010, p. 21 entre outros).

Nos Estados Unidos, a pesquisa das crenças de estudantes de inglês como segunda língua (L2) ${ }^{2}$ começou a se popularizar na década de 1980. Já no Brasil, a pesquisa de crenças de estudantes de inglês como língua estrangeira (LE) teve início na década de 1990 .

Segundo Barcelos (2007a, p. 28), a pesquisa sobre crenças no Brasil está dividida cronologicamente em três períodos, a saber: período inicial, de 1990 a 1995; período de desenvolvimento e consolidação, de 1996 a 2001; e o período de expansão, de 2002 até o presente. Percebe-se que a pesquisa de crenças tem alcançado notável desenvolvimento mesmo na área de Linguística Aplicada (SILVA, 2010).

Apesar do crescimento e da produção extensa acima referida, este campo ainda carece de crenças mais específicas (BARCELOS, 2004) e "ainda sabemos muito pouco sobre as funções das crenças na cultura da sala de aula" (BARCELOS, 2003 , p. 27). Ainda, Barcelos ressalta o fato de que "existem poucos trabalhos com professores e alunos de outras línguas estrangeiras (que não sejam o inglês), e que (um trabalho como esse) precisa fazer parte de uma agenda futura de investigação de crenças" (2007, p. 60, palavras entre parênteses nossas).

No caso específico das pesquisas em crenças no ensino-aprendizagem de japonês como LE (doravante JLE) no Brasil, por sua vez, elas ainda restam como um tema pouco estudado (MUKAI; ÖZERHAN, 2011). De fato, o número de trabalhos publicados sobre crenças de professores e alunos de JLE ainda é pequeno, comparado aos demais idiomas estrangeiros. Isso se deve ao fato de que os primeiros trabalhos foram apresentados só em 2010 como monografia de conclusão de curso de graduação (cf. BREYER, 2010; FEIJÓ, 2010), e os primeiros artigos foram publicados em 2011 (cf. MUKAI, 2011a, 2011b, 2011c).

2. Nos Estudos da Aquisição-Aprendizagem de LE/L2, as noções LE e L2 diferenciam-se com base no contexto onde se aprende uma língua estrangeira: caso se aprenda o inglês nos países ou comunidade em que não se fala/utiliza essa mesma língua como meio de comunicação, é considerada como língua estrangeira (LE); caso se aprenda o inglês, por exemplo, nos países ou comunidade em que se fala/utiliza essa mesma língua como meio de comunicação, é considerada como segunda língua (L2). Neste artigo, utilizaremos os termos LE e L2 separadamente, conforme afirmado acima. 
Diante do exposto, este estudo tem como objetivo investigar e discutir o estado da arte sobre as pesquisas em crenças no ensino-aprendizagem de JLE no Brasil, por meio de uma compilação dos trabalhos publicados e/ou realizados até o presente momento. Através de uma meta-análise qualitativa sobre os estudos de crenças nessa área, apontaremos e discutiremos as suas questões metodológicas, para que possamos refleti-las para futuras pesquisas. As perguntas de pesquisa que norteiam o nosso trabalho são: Quais pesquisas em crenças no ensino-aprendizagem de JLE no Brasil têm sido realizadas até hoje? Quais problemas metodológicos as referidas pesquisas apresentam?

\section{Conceito de Crenças $^{3}$}

As crenças, tratadas como uma das variáveis individuais na Linguística Aplicada, podem ser definidas, em um sentido amplo, como opiniões e ideias que professores e alunos têm a respeito dos processos de ensino-aprendizagem de línguas (BARCELOS, 2001, p. 72) ou "algo como pensamentos, palavras e crenças que as pessoas têm sobre o ensino-aprendizagem de LE” (THE JAPAN FOUNDATION [Org.], 2006).

Quando o estudo sobre crenças dos aprendizes se popularizou, as crenças eram consideradas meramente "conceitos e preconceitos relativos ao estudo de determinada língua estrangeira" (HORWITZ, 1987) ou como sinônimo de conhecimento metacognitivo (WENDEN, 1999). Segundo as autoras, as crenças eram concebidas como estáveis e imutáveis, sendo geradas na mente do aprendiz. Assim, naquela época, era importante apenas identificar as crenças dos alunos sem considerar suas experiências do passado, ações e contexto social em que estavam inseridos.

Barcelos (2004, p. 132), no entanto, considera que "as crenças não são somente um conceito cognitivo, mas também social, porque nascem de nossas experiências e problemas, de nossa interação com o contexto e da nossa capacidade de refletir e pensar sobre o que nos cerca". Barcelos (2006, p. 18) afirma que crenças são

\footnotetext{
uma forma de pensamento, construções da realidade, maneiras de ver e perceber o mundo e seus fenômenos, co-construídas em nossas experiências resultantes de um processo interativo de interpretação e (re)significação. Como tal, crenças são sociais (mas também individuais), dinâmicas, contextuais e paradoxais.
}

Essa posição teórica é vista, também, em Kalaja (1995) que considera crenças como dinâmicas, sociais e contextuais. Percebe-se que hoje, tanto para Barcelos (2004, 2006) quanto para Kalaja (1995), as crenças não devem ser consideradas apenas como processo cognitivo, mas, sim, como processo interativo e socialmente construído, inserido em um contexto, podendo variar de acordo com o aprendiz e o contexto e até

3. Quanto à nossa posição mais detalhada, vide Mukai; Conceição (2012). Para uma revisão extensa sobre o assunto, vide Barcelos (2003, 2004), Silva (2010) entre outros. 
dentro de um mesmo contexto. Ou seja, as crenças são vistas como não estáveis, sociais, dinâmicas, contextuais e paradoxais, uma vez que nascem das experiências atuais e passadas, sendo formadas com base na interação e na adaptação junto ao ambiente em que estamos inseridos (BARCELOS, 2006, 2007).

Concebemos, então, crenças como interativas e socialmente coconstruídas a partir das nossas experiências anteriores e presentes, sendo ininterruptamente configuradas e refletidas com base na ação, interação e adaptação dos indivíduos a seus contextos específicos (MUKAI, 2014).

\section{Crenças no Ensino-Aprendizagem de Japonês no Brasil}

Conforme Barcelos (2000), os estudos de crenças ajudariam a solucionar questões como a ansiedade na aprendizagem de línguas e conflitos entre as crenças de professores e alunos ou entre as crenças de um professor em relação às do(s) outro(s), além de contribuir para compreensão das atitudes, ações e motivações dos aprendizes e professores de línguas. Como Mukai (2011c) aponta, por mais que um professor domine técnicas de ensino, o ensino de uma LE pode acabar fracassando, se seu ponto de vista e o do aluno e/ou de outro professor forem muito distintos. Ou seja, a pesquisa das crenças dos agentes engajados no ensino-aprendizagem de línguas é imprescindível.

As crenças quanto ao ensino-aprendizagem de LE/L2 podem ser divididas, principalmente, em: (1) crenças dos estudantes de LE/L2; (2) crenças dos professores de LE/L2; (3) crenças dos coordenadores e diretores escolares; e (4) crenças dos pais dos alunos.

Por exemplo, temos a crença de que conversação/falar é o mais importante em uma aula de JLE, que é uma crença de estudantes a respeito da metodologia/quatro habilidades linguísticas (cf. FEIJÓ, 2010). Outro exemplo é a crença de estudantes de que um professor de japonês devia ser japonês ou nipo-descendente para ter um bom desempenho, uma crença relativa aos atributos do professor (cf. MARTINEZ, 2013). Conforme Barcelos (2001), as crenças são pessoais, contextuais, episódicas e têm origem nas experiências, na cultura e no folclore, podendo ser internamente inconscientes e contraditórias.

No que se refere às pesquisas já realizadas sobre crenças no ensino-aprendizagem de JLE no Brasil, destacaremos, nesta seção, alguns trabalhos.

Feijó (2010) investigou qualitativamente as crenças de dois alunos universitários do nível intermediário sobre a habilidade de fala em japonês, partindo dos questionamentos e preocupações dos mesmos a respeito dessa habilidade. Os resultados sugerem que as experiências (de aprendizagem de outras línguas) anteriores dos alunos influenciam nas suas crenças e que estas também influenciam nas suas ações e nas suas escolhas das estratégias de aprendizagem. A autora conclui que professores devem refletir sobre o processo de ensino-aprendizagem da expressão oral, para que seus alunos não se sintam inseguros e despreparados no uso de sua habilidade oral no idioma japonês. 
Breyer (2010) analisou de forma qualitativa as crenças de três alunos universitários do nível intermediário no contexto de ensino-aprendizagem de JLE, bem como a relação existente entre as crenças e as experiências desses alunos. Os resultados mostraram que a língua japonesa é considerada difícil por ser tão diferente da língua portuguesa. Entre as dificuldades encontradas no processo de aprendizagem foram citadas a linguagem de tratamento (keigo) e a memorização de ideogramas (kanji). Observou-se, também, uma influência das crenças de outros, tanto em relação à motivação quanto à desmotivação dos mesmos. Segundo a autora, os participantes apresentam uma insatisfação com relação ao domínio da língua japonesa e, com o passar do tempo, se sentem desmotivados em prosseguir os estudos.

Martinez (2013) realizou um estudo longitudinal sobre as crenças e motivações de doze alunos não descendentes de japoneses do primeiro estágio no curso de japonês oferecido em um Centro de estudos de línguas (CEL) de uma escola pública da zona sul da cidade de São Paulo. O resultado dessa pesquisa mostrou que, no decorrer do semestre, as crenças dos participantes foram alteradas. No início do semestre, os participantes acreditavam que o japonês era uma língua muito difícil e que um professor de japonês devia ser japonês ou nipo-descendente para ter um bom desempenho. No estágio final da pesquisa, no entanto, os alunos manifestaram que a língua japonesa não era tão difícil quanto eles imaginavam que fosse e que um professor poderia ser não descendente de japoneses e ainda assim ser competente para dar aulas de japonês. $\mathrm{O}$ resultado dessa pesquisa condiz com o que Alvarez afirma: as crenças não são um componente fixo, mas "podem ser modificadas com o tempo, atendendo às necessidades do indivíduo e a redefinição de seus conceitos, se convencido de que tal modificação the trará benefícios" (2007, p. 200).

Oliveira (2013) discorreu sobre as crenças e suas relações com as estratégias de aprendizagem de quatro alunos universitários a respeito da escrita da língua japonesa, em especial a aprendizagem dos ideogramas (kanji). Segundo o autor, os participantes dessa pesquisa têm a crença de que a aprendizagem de kanji é difícil, motivo que os leva utilizar diversas estratégias de aprendizagem, dentre elas, estratégias cognitivas de repetição e frequência e estratégias de compensação com maior frequência. Contudo, segundo o autor, os participantes não pareciam estar cientes do uso dessas estratégias de aprendizagem e da importância das mesmas. Constatou-se, também, que o uso de estratégias de aprendizagem metacognitivas, isto é, estratégias para o gerenciamento da aprendizagem, era inferior ao uso das demais estratégias de aprendizagem, demonstrando assim que os participantes pareciam refletir pouco sobre suas práticas na aprendizagem de kanji. Apesar disso, segundo o autor, os participantes demonstraram saber por quais meios devem seguir para alcançar a solução de tarefas específicas propostas.

Já a dissertação de Hayashi (2015) trata de um estudo de caso sobre investigação de crenças, experiências e ações de aprendizes e professores de JLE de uma universidade pública do Distrito Federal, no que se refere ao material didático do mesmo idioma. Os resultados obtidos mostram uma estreita relação entre as crenças, experiências 
dos aprendizes e dos professores, influenciando significativamente as ações desses participantes em sala de aula. Além disso, o material didático mostrou-se uma ferramenta mediadora de experiências cognitivas em sala de aula, motivando as ações e experiências sociais dos participantes, as quais contribuem para o processo de formação das crenças. Por fim, a análise demonstra haver uma relação de correspondência, na qual muitas crenças e experiências dos aprendizes aparecem refletidas nas crenças dos professores e vice-versa.

No que se refere às pesquisas sobre crenças de professores de JLE, por sua vez, Nascimento (2013) investigou a influência das crenças nas ações de três professores universitários com perfis diferenciados: uma professora que adquiriu a língua japonesa como língua materna (LM), outra que adquiriu/aprendeu em contexto de língua de herança $(\mathrm{LH})$ e, por fim, um professor que aprendeu como língua estrangeira (LE). Os resultados demonstraram que, embora tenham tido trajetórias diferenciadas de aquisição/aprendizagem da língua japonesa, os professores participantes dessa pesquisa possuem não apenas crenças contrárias entre si, mas também crenças semelhantes em relação ao ensino de JLE no Brasil, demonstrando que o ambiente de trabalho foi capaz de promover momentos de ressignificação das crenças dos professores participantes. Nesse estudo foi ainda possível constatar que as crenças dos professores participantes influenciam no modo como eles organizam e definem suas ações em sala de aula.

\title{
3. Metodologia Empregada
}

Realizamos uma meta-análise qualitativa sobre as pesquisas em crenças no ensino-aprendizagem de JLE no Brasil. Segundo Rodrigues (2002, p. 26),

\begin{abstract}
uma meta-análise qualitativa procura identificar, através de determinadas categorias, semelhanças e controvérsias numa quantidade de estudos da mesma área de pesquisa. Tratase, na verdade, de um processo de descrição interpretativa, orientado por determinadas categorias teóricas. O resultado final é uma visão mais acurada do desenvolvimento da área analisada.
\end{abstract}

Para a realização de nossa meta-análise, foram definidas, conforme os objetivos deste trabalho (cf. Introdução), seis categorias de análise, a saber: (1) modalidade de publicação, (2) autores/ano de publicação/instituição, (3) foco da pesquisa, (4) participantes da pesquisa, (5) método/natureza de pesquisa e (6) instrumentos de coleta de dados.

Procuramos obter um maior número de estudos possível. No entanto, pode acontecer que um ou outro estudo não tenha sido objeto de análise devido às dificuldades na localização de determinados estudos. Apesar dessas dificuldades, o esforço foi feito para a obtenção de estudos representativos da área, o que nos permitiu uma compreensão e análise do estado da arte em estudos sobre crenças no contexto em questão. 


\section{Resultado}

A seguir será apresentado um quadro com os estudos sobre crenças nos quais foram aplicadas as categorias de análise.

\section{Quadro 1 - Cenário brasileiro de pesquisas sobre crenças no ensino- aprendizagem de japonês como LE}

\begin{tabular}{|c|c|c|c|c|c|}
\hline $\begin{array}{c}\text { Modalidade } \\
\text { de } \\
\text { publicação } \\
\text { (Categoria 1) }\end{array}$ & $\begin{array}{l}\text { Autores/ano/ } \\
\text { instituição } \\
\text { (Categoria 2) }\end{array}$ & $\begin{array}{l}\text { Foco da pesquisa } \\
\text { (Categoria 3) }\end{array}$ & $\begin{array}{c}\text { Partici- } \\
\text { pantes da } \\
\text { pesquisa } \\
\text { (Categoria 4) }\end{array}$ & $\begin{array}{c}\text { Método/ } \\
\text { Natureza de } \\
\text { pesquisa } \\
\text { (Categoria 5) }\end{array}$ & $\begin{array}{l}\text { Instrumentos de } \\
\text { coleta de dados } \\
\text { (Categoria 6) }\end{array}$ \\
\hline $\begin{array}{l}\text { Capítulo de } \\
\text { livro }\end{array}$ & $\begin{array}{l}\text { Mukai; Conceição } \\
\text { (2012) (UnB) }\end{array}$ & $\begin{array}{l}\text { Crenças, ações e reflexões } \\
\text { de uma aluna do ensino } \\
\text { superior sobre seu próprio } \\
\text { aprendizado }\end{array}$ & $\begin{array}{l}\text { Uma aluna } \\
\text { do ensino } \\
\text { superior }\end{array}$ & $\begin{array}{l}\text { Qualitativo; } \\
\text { Estudo de caso } \\
\text { interpretativo }\end{array}$ & $\begin{array}{l}\text { 1) questionário } \\
\text { fechado } \\
\text { 2) narrativa escrita } \\
\text { 3) entrevista semi- } \\
\text { estruturada }\end{array}$ \\
\hline \multirow[b]{3}{*}{$\begin{array}{l}\text { Artigos em } \\
\text { periódicos }\end{array}$} & $\begin{array}{l}\text { Mukai (2011a) } \\
\text { (UnB) }\end{array}$ & $\begin{array}{l}\text { Crenças e necessidades de } \\
\text { aprendizes de JLE do nível } \\
\text { intermediário do ensino } \\
\text { superior sobre a habilidade } \\
\text { de escrita e materiais } \\
\text { didáticos }\end{array}$ & $\begin{array}{l}\text { Aprendizes } \\
\text { de JLE do } \\
\text { nível } \\
\text { intermediário } \\
\text { do ensino } \\
\text { superior } \\
\end{array}$ & $\begin{array}{l}\text { Qualitativo; } \\
\text { Estudo de caso } \\
\text { interpretativo }\end{array}$ & $\begin{array}{l}\text { 1) questionário } \\
\text { 2) entrevista }\end{array}$ \\
\hline & $\begin{array}{l}\text { Fukushi; Mukai } \\
\text { (2012) (UnB) }\end{array}$ & $\begin{array}{l}\text { Crenças e necessidades de } \\
\text { aprendizes do ensino } \\
\text { superior sobre a habilidade } \\
\text { de fala e a metodologia de } \\
\text { ensino }\end{array}$ & $\begin{array}{l}\text { Aprendizes } \\
\text { do ensino } \\
\text { superior }\end{array}$ & $\begin{array}{l}\text { Qualitativo; } \\
\text { Estudo de caso } \\
\text { interpretativo }\end{array}$ & $\begin{array}{l}\text { 1) questionário } \\
\text { misto } \\
\text { 2) observação de } \\
\text { aulas com notas de } \\
\text { campo } \\
\text { 3) gravação das } \\
\text { aulas cm áudio } \\
\text { 4) entrevista } \\
\text { semiestruturada }\end{array}$ \\
\hline & $\begin{array}{l}\text { Mukai (2014) } \\
\text { (UnB) }\end{array}$ & $\begin{array}{l}\text { Crenças e necessidades em } \\
\text { relação à escrita em japonês: } \\
\text { nos casos dos estudantes } \\
\text { universitários brasileiros e } \\
\text { portugueses }\end{array}$ & $\begin{array}{l}10 \text { alunos } \\
\text { brasileiros e } \\
10 \text { alunos } \\
\text { portugueses } \\
\text { do ensino } \\
\text { superior }\end{array}$ & $\begin{array}{l}\text { Qualitativo; } \\
\text { Estudo de caso } \\
\text { interpretativo } \\
\text { e comparativo }\end{array}$ & $\begin{array}{l}\text { Para brasileiros, } \\
\text { 1) questionário } \\
\text { 2) entrevista semi- } \\
\text { estruturada (gravada } \\
\text { em áudio); } \\
\text { 3) redação } \\
\text { Para portugueses, } \\
\text { 1) o mesmo } \\
\text { questionário acima } \\
\text { mencionado } \\
\text { 2) follow-up email } \\
\text { (perguntas } \\
\text { adicionais feitas via } \\
\text { e-mail após a } \\
\text { aplicação do } \\
\text { questionário) } \\
\text { 3) observação de } \\
\text { aulas com notas de } \\
\text { campo } \\
\text { 4) redação }\end{array}$ \\
\hline \multirow[t]{2}{*}{ Anais } & $\begin{array}{l}\text { Feijó; Mukai } \\
\text { (2012) (UnB) }\end{array}$ & $\begin{array}{l}\text { Crenças de aprendizes do } \\
\text { ensino superior sobre a } \\
\text { habilidade de fala }\end{array}$ & $\begin{array}{l}\text { Aprendizes } \\
\text { do ensino } \\
\text { superior }\end{array}$ & $\begin{array}{l}\text { Qualitativo; } \\
\text { Estudo de caso } \\
\text { interpretativo }\end{array}$ & $\begin{array}{l}\text { 1) questionário } \\
\text { semiaberto } \\
\text { 2) questionário } \\
\text { fechado } \\
\text { 3) observação de } \\
\text { aulas } \\
\text { 4) notas de } \\
\text { campo } \\
\text { 5) entrevista semi- } \\
\text { estruturada } \\
\text { 6) narrativas } \\
\text { 7) metáforas }\end{array}$ \\
\hline & $\begin{array}{l}\text { Mukai (2014) } \\
\text { (UnB) }\end{array}$ & $\begin{array}{l}\text { Estudos de crenças para } \\
\text { professores e alunos no } \\
\text { ensino-aprendizagem de LJE }\end{array}$ & -- & $\begin{array}{l}\text { Abordagem } \\
\text { teórica }\end{array}$ & -- \\
\hline \multirow{2}{*}{$\begin{array}{l}\text { Revistas de } \\
\text { uma escola de } \\
\text { idioma } \\
\text { japonês }\end{array}$} & $\begin{array}{l}\text { Mukai (2011b) } \\
\text { (UnB) }\end{array}$ & $\begin{array}{l}\text { Estudos de crenças para } \\
\text { professores de JLE }\end{array}$ & -- & $\begin{array}{l}\text { Abordagem } \\
\text { teórica }\end{array}$ & -- \\
\hline & $\begin{array}{l}\text { Mukai }(2011 \mathrm{c}) \\
(\mathrm{UnB})\end{array}$ & $\begin{array}{l}\text { Crenças de aprendizes do } \\
\text { ensino superior sobre a }\end{array}$ & $\begin{array}{l}\text { Aprendizes } \\
\text { do ensino }\end{array}$ & $\begin{array}{l}\text { Qualitativo; } \\
\text { Estudo de caso }\end{array}$ & $\begin{array}{l}\text { 1) questionário } \\
\text { 2) entrevista }\end{array}$ \\
\hline
\end{tabular}




\begin{tabular}{|c|c|c|c|c|c|}
\hline & & $\begin{array}{l}\text { habilidade de escrita em } \\
\text { japonês }\end{array}$ & superior & interpretativo & \\
\hline \multirow{4}{*}{$\begin{array}{l}\text { Dissertações } \\
\text { de mestrado }\end{array}$} & $\begin{array}{l}\text { Oliveira (2013) } \\
\text { (UnB) }\end{array}$ & $\begin{array}{l}\text { Crenças de aprendizes do } \\
\text { ensino superior sobre as } \\
\text { estratégias de aprendizagem } \\
\text { de kanji (ideogramas) }\end{array}$ & $\begin{array}{l}\text { Aprendizes } \\
\text { do ensino } \\
\text { superior }\end{array}$ & $\begin{array}{l}\text { Qualitativo; } \\
\text { Estudo de caso } \\
\text { interpretativo }\end{array}$ & $\begin{array}{l}\text { 1) entrevista semi- } \\
\text { estruturada } \\
\text { 2) questionário com } \\
\text { escala likert } \\
\text { 3) narrativa escrita } \\
\text { 4) observação de } \\
\text { aulas com notas de } \\
\text { campo }\end{array}$ \\
\hline & $\begin{array}{l}\text { Nascimento } \\
\text { (2013) (UnB) }\end{array}$ & $\begin{array}{l}\text { Influência das crenças nas } \\
\text { ações de professores } \\
\text { universitários com trajetórias } \\
\text { diferenciadas de } \\
\text { aquisição/aprendizagem } \\
\text { (LM, LH e LE) }\end{array}$ & $\begin{array}{l}3 \text { professores } \\
\text { universitários }\end{array}$ & $\begin{array}{l}\text { Qualitativo; } \\
\text { Estudo de caso } \\
\text { interpretativo }\end{array}$ & $\begin{array}{l}\text { 1) questionário } \\
\text { escrito misto } \\
\text { 2) observação de } \\
\text { aulas com notas de } \\
\text { campo e gravações } \\
\text { em áudio } \\
\text { 3) narrativa escrita } \\
\text { 4) entrcvista } \\
\text { semiestruturada }\end{array}$ \\
\hline & $\begin{array}{l}\text { Hayashi (2015) } \\
\text { (UnB) }\end{array}$ & $\begin{array}{l}\text { Crenças, experiências e } \\
\text { ações dos aprendizes e } \\
\text { professores universitários } \\
\text { sobre o material didático de } \\
\text { língua japonesa (como LE) } \\
\text { na universidade }\end{array}$ & $\begin{array}{l}\text { Aprendizes e } \\
\text { professores } \\
\text { do ensino } \\
\text { superior }\end{array}$ & $\begin{array}{l}\text { Qualitativo; } \\
\text { Estudo de caso } \\
\text { interpretativo }\end{array}$ & $\begin{array}{l}\text { 1) entrevista semi- } \\
\text { estruturada } \\
\text { b) narrativa escrita } \\
\text { 3) questionário } \\
\text { escrito misto } \\
\text { 4) observação de } \\
\text { aulas com notas de } \\
\text { campo }\end{array}$ \\
\hline & $\begin{array}{l}\text { Lima (2015) } \\
\text { (USP) }\end{array}$ & $\begin{array}{l}\text { Um estudo sobre crenças de } \\
\text { professores nikkeis: } \\
\text { abordagens de ensino em } \\
\text { uma escola de colônia }\end{array}$ & $\begin{array}{l}2 \text { professoras } \\
\text { descendentes } \\
\text { de imigrantes } \\
\text { japoneses de } \\
\text { uma escola } \\
\text { comunitária } \\
\text { de nipo- } \\
\text { brasileiros }\end{array}$ & $\begin{array}{l}\text { Qualitativo; } \\
\text { Estudo de caso } \\
\text { etnográfico }\end{array}$ & $\begin{array}{l}\text { 1) observação não } \\
\text { 2) gravação em } \\
\text { audio das aulas } \\
\text { 3) notas de campo } \\
\text { 4) entrevista }\end{array}$ \\
\hline \multirow{4}{*}{$\begin{array}{l}\text { Monografias } \\
\text { de conclusão } \\
\text { de curso de } \\
\text { especialização }\end{array}$} & $\begin{array}{l}\text { Oshiro (2013) } \\
\text { (USP) }\end{array}$ & $\begin{array}{l}\text { Crenças de uma aluna nipo- } \\
\text { brasileira de uma escola } \\
\text { particular de japonês sobre } \\
\text { seu aprendizado de JLE }\end{array}$ & $\begin{array}{l}\text { Uma aluna } \\
\text { nipo- } \\
\text { brasileira de } \\
\text { uma escola } \\
\text { particular de } \\
\text { japonês }\end{array}$ & $\begin{array}{l}\text { Qualitativo; } \\
\text { Estudo de caso } \\
\text { interpretativo }\end{array}$ & $\begin{array}{l}\text { 1) questionário } \\
\text { misto } \\
\text { 2) questionário } \\
\text { fechado BALLI } \\
\text { adaptado } \\
\text { 3) narrativa escrita } \\
\text { 4) observação de } \\
\text { aula com notas de } \\
\text { campo } \\
\text { 5) entrevista semi- } \\
\text { estruturada }\end{array}$ \\
\hline & $\begin{array}{l}\text { Ishida (2013) } \\
\text { (USP) }\end{array}$ & $\begin{array}{l}\text { Crenças e motivações de } \\
\text { aprendizes do CEL em São } \\
\text { Paulo sobre seu aprendizado } \\
\text { de ЛLE }\end{array}$ & $\begin{array}{l}\text { Aprendizes } \\
\text { do CEL }\end{array}$ & $\begin{array}{l}\text { Qualitativo; } \\
\text { Estudo de caso } \\
\text { interpretativo }\end{array}$ & $\begin{array}{l}\text { 1) questionário } \\
\text { misto (fechado e } \\
\text { aberto) } \\
\text { 2) entrevista semi- } \\
\text { estruturada }\end{array}$ \\
\hline & $\begin{array}{l}\text { Martinez (2013) } \\
\text { (USP) }\end{array}$ & $\begin{array}{l}\text { Crenças e motivações de } \\
\text { aprendizes sem ascendência } \\
\text { japonesa do CEL em São } \\
\text { Paulo sobre seu aprendizado } \\
\text { de ЛE }\end{array}$ & $\begin{array}{l}\text { Aprendizes } \\
\text { sem } \\
\text { ascendência } \\
\text { japonesa do } \\
\text { CEL }\end{array}$ & $\begin{array}{l}\text { Qualitativo; } \\
\text { Estudo de caso } \\
\text { interpretativo }\end{array}$ & $\begin{array}{l}\text { 1) questionário } \\
\text { misto } \\
\text { 2) narrativa escrita } \\
\text { 3) entrevista semi- } \\
\text { estruturada. }\end{array}$ \\
\hline & $\begin{array}{l}\text { Feijó (2010) } \\
\text { (UnB) }\end{array}$ & $\begin{array}{l}\text { Crenças de aprendizes do } \\
\text { ensino superior sobre a } \\
\text { habilidade de fala }\end{array}$ & $\begin{array}{l}\text { Aprendizes } \\
\text { do ensino } \\
\text { superior }\end{array}$ & $\begin{array}{l}\text { Qualitativo; } \\
\text { Estudo de caso } \\
\text { interpretativo }\end{array}$ & $\begin{array}{l}\text { 1) questionário } \\
\text { semiaberto } \\
\text { 2) questionário } \\
\text { fechado } \\
\text { 3) observação de } \\
\text { aulas } \\
\text { 4) notas de } \\
\text { campo }\end{array}$ \\
\hline
\end{tabular}




\begin{tabular}{|c|c|c|c|c|c|}
\hline \multirow{5}{*}{$\begin{array}{l}\text { Monografias } \\
\text { de conclusão } \\
\text { de curso de } \\
\text { graduação }\end{array}$} & & & & & $\begin{array}{l}\text { 5) entrevista semi- } \\
\text { estruturada } \\
\text { 6) narrativa escrita } \\
\text { 7) metáfora }\end{array}$ \\
\hline & $\begin{array}{l}\text { Breyer (2010) } \\
\text { (UnB) }\end{array}$ & $\begin{array}{l}\text { Crenças e experiências de } \\
\text { aprendizes do ensino } \\
\text { superior sobre seu } \\
\text { aprendizado de JLE }\end{array}$ & $\begin{array}{l}\text { Aprendizes } \\
\text { do ensino } \\
\text { superior }\end{array}$ & $\begin{array}{l}\text { Qualitativo; } \\
\text { Estudo de caso } \\
\text { interpretativo }\end{array}$ & $\begin{array}{l}\text { 1) questionário } \\
\text { sociocultural } \\
\text { 2) narrativa escrita } \\
\text { 3) narrativa visual } \\
\text { 4) entrevista } \\
\text { semiestruturada } \\
\text { gravada em áudio }\end{array}$ \\
\hline & $\begin{array}{l}\text { Fukushi (2012) } \\
\text { (UnB) }\end{array}$ & $\begin{array}{l}\text { Crenças de uma professora e } \\
\text { dos alunos sobre a } \\
\text { metodologia de ensino de } \\
\text { JLE no que se refere ao } \\
\text { desenvolvimento da } \\
\text { habilidade de fala }\end{array}$ & $\begin{array}{l}\text { Aprendizes e } \\
\text { uma } \\
\text { professora do } \\
\text { ensino } \\
\text { superior }\end{array}$ & $\begin{array}{l}\text { Qualitativo; } \\
\text { Estudo de caso } \\
\text { interpretativo }\end{array}$ & $\begin{array}{l}\text { 1) questionário } \\
\text { misto aplicados à } \\
\text { professora c aos } \\
\text { alunos } \\
\text { 2) observação de } \\
\text { aulas com notas de } \\
\text { campo, gravações } \\
\text { das aulas cm áudio } \\
\text { 3) entrevista } \\
\text { semiestruturada } \\
\text { feita com a } \\
\text { professora e com os } \\
\text { alunos }\end{array}$ \\
\hline & $\begin{array}{l}\text { Umetsu (2013) } \\
\text { (UnB) }\end{array}$ & $\begin{array}{l}\text { Influências das crenças de } \\
\text { aprendizes acerca do corpo } \\
\text { docente de um curso } \\
\text { superior em relação à sua } \\
\text { aprendizagem }\end{array}$ & $\begin{array}{l}\text { Aprendizes } \\
\text { do ensino } \\
\text { superior }\end{array}$ & $\begin{array}{l}\text { Qualitativo; } \\
\text { Estudo de caso } \\
\text { interpretativo }\end{array}$ & $\begin{array}{l}\text { 1) questionário } \\
\text { misto } \\
\text { 2) observação de } \\
\text { aulas com notas de } \\
\text { campo e gravações } \\
\text { em áudio } \\
\text { 3) entrevista } \\
\text { semiestruturada }\end{array}$ \\
\hline & $\begin{array}{l}\text { Yassui (2015) } \\
\text { (UnB) }\end{array}$ & $\begin{array}{l}\text { Crenças a respeito das } \\
\text { estratégias de aprendizagem } \\
\text { dos kanji da língua japonesa }\end{array}$ & $\begin{array}{l}\text { Aprendizes } \\
\text { do ensino } \\
\text { superior }\end{array}$ & $\begin{array}{l}\text { Qualitativo; } \\
\text { Estudo de caso } \\
\text { interpretativo }\end{array}$ & $\begin{array}{l}\text { 1) questionário } \\
\text { misto (questionário } \\
\text { Likert com } \\
\text { adaptaçōes) } \\
\text { 2) observação de } \\
\text { aulas com notas de } \\
\text { campo } \\
\text { 3) entrevista } \\
\text { semiestruturada } \\
\text { com gravação de } \\
\text { ádio }\end{array}$ \\
\hline
\end{tabular}

\section{(Quadro nosso)}

Obs.: UnB = Universidade de Brasília; USP = Universidade de São Paulo; CEL = Centro de estudos de línguas.

Conforme o quadro acima, percebe-se que as investigações sobre crenças no ensino-aprendizagem de JLE no Brasil começaram somente após 2010 e com isso, podemos afirmar que esta área ainda se encontra no "período inicial" de sua história, diferente da área de ensino-aprendizagem de inglês, que está no período de expansão (cf. Introdução).

Com relação à modalidade de publicação (cf. categoria 1), foram constatados, nos últimos seis anos, 1 capítulo de livro, 3 artigos em periódicos, 2 artigos em anais, 2 artigos em revistas de uma escola de idioma japonês, 4 dissertações de mestrado, 3 monografias de curso de especialização e 5 monografias de conclusão de curso de 
graduação, totalizando 20 artigos relacionados ao estudo em crenças no ensinoaprendizagem de JLE no Brasil. Apesar de certo crescimento dos trabalhos nessa área, nota-se que, quanto às instituições onde se deram as pesquisas (cf. categoria 2), concentram-se apenas na Universidade de Brasília e na Universidade de São Paulo.

Apesar de a área de crenças sobre JLE se encontrar no "período inicial", os estudos tratam daquelas mais específicas (cf. categoria 3), tais como a habilidade de escrita, oralidade, aprendizagem e estratégias de kanji (ideogramas), materiais didáticos, metodologia de ensino, etc. No entanto, a maioria dos trabalhos aborda crenças de alunos de JLE, encontrando apenas quatro pesquisas que envolvem professores de JLE (cf. FUKUSHI, 2012; HAYASHI, 2015; LIMA, 2015; NASCIMENTO, 2013) (cf. categoria 4). Com relação ao contexto da pesquisa, também não há muita variedade, sendo predominante o ensino superior. Apenas quatro pesquisas se deram em uma escola particular ou no CEL ligado ao ensino médio público.

No que se refere ao método e natureza de pesquisa (cf. categoria 5), na grande maioria das pesquisas em questão, utilizou-se o método qualitativo com a natureza de um estudo de caso interpretativo.

Segundo Freebody (2003), a pesquisa qualitativa divide-se em três grandes áreas de investigação: estudo de caso, etnografia e pesquisa-ação. E, ainda, quanto ao estudo de caso, Faltis (1997) faz a distinção de dois tipos: interpretativo e interventivo. Diante disso, percebe-se que, mesmo a pesquisa sendo qualitativa, a sua grande maioria é um estudo de caso "interpretativo" (cf. categoria 5), existindo apenas uma pesquisa que se configura como estudo de caso etnográfico (cf. LIMA, 2015). Em outras palavras, ainda não foram realizadas as pesquisas cujo delineamento é considerado pesquisa-ação ou estudo de caso interventivo. Ainda, convém ressaltar o fato de que a abordagem quantitativa não foi aplicada, até hoje, nas pesquisas em crenças no ensino-aprendizagem de JLE no Brasil.

Verificamos, ainda, que, na maioria das pesquisas, empregaram-se mais de três tipos de instrumentos diferentes para coleta de dados qualitativos, visando à triangulação dos dados (cf. categoria 6). No entanto, mesmo sendo utilizados os instrumentos variados, a sua maioria é questionário misto, observação de aulas, entrevista semiestruturada e/ou narrativa escrita, o que nos permite afirmar que há uma variedade tendenciosa no que se refere à utilização de instrumentos para coleta de dados. Dependendo dos objetivos de pesquisa, poderiam ser aplicados demais instrumentos qualitativos, como a técnica introspectiva do protocolo verbal, a sessão de reflexão (visionamento), a gravação em vídeo, o diário reflexivo (tanto do aprendiz quanto do professor), entre outros.

\section{Considerações finais}

Vimos que as pesquisas sobre crenças no ensino-aprendizagem de JLE no Brasil começaram somente após 2010, ou seja, a área em questão ainda se encontra no "período inicial" de sua história. No entanto, foi verificado que os seus estudos tratam daquelas 
crenças mais específicas, tais como a habilidade de escrita, oralidade, aprendizagem e estratégias de kanji (ideogramas), materiais didáticos, metodologia de ensino, etc. Podemos considerar, então, que existe certa variedade quanto ao foco da pesquisa, mas os resultados mostraram que a maioria aborda crenças de alunos (não de professores), sendo predominante o ensino superior como contexto de pesquisa.

Com relação às questões metodológicas, foi relevado que, na grande maioria das pesquisas em questão, se utilizou predominantemente o método qualitativo com a natureza de um estudo de caso interpretativo. Ou seja, o método quantitativo ainda não foi empregado e mesmo o método sendo qualitativo, a etnografia, a pesquisa-ação e o estudo de caso interventivo ainda não foram aplicados no âmbito brasileiro de JLE até hoje.

Diante desse estado da arte, podemos afirmar que serão igualmente importantes investigações sobre crenças de professores e de terceiros (coordenador, diretor, dono da escola, pais dos alunos), pesquisas configuradas como uma pesquisa-ação ou um estudo de caso interventivo, bem como pesquisas com a abordagem quantitativa, para que possamos compreender melhor, de forma holística, o contexto brasileiro de ensinoaprendizagem de JLE.

\section{Referências Bibliográficas}

ALVAREZ, M. L. O. Crenças, motivações e expectativas de alunos de um curso de formação Letras/Espanhol. In: ALVAREZ, M. L. O.; SILVA, K, A. da (Orgs.). Linguística Aplicada: múltiplos olhares. 1. ed. Campinas-São Paulo: Pontes Editores, 2007. p. 191-231.

BARCELOS, A. M. F. Metodologia de pesquisa das crenças sobre aprendizagem de línguas: estado da arte. In: Revista Brasileira de Linguística Aplicada, v. 1, n. 1, p. 71-92, 2001.

. Researching beliefs about SLA: a critical review. In: KALAJA, P.; BARCELOS, A. M. F. (Orgs.). Beliefs about SLA: New Research Approaches. Dordrecht: Kluwer, 2003a. p. 7-33.

. Teachers' and students' beliefs within a Deweyan framework: conflict and influence. In: KALAJA, P.; BARCELOS, A. M. F. (Orgs.). Beliefs about SLA: New Research Approaches. Dordrecht: Kluwer, 2003b. p. 171-199.

. Crenças sobre aprendizagem de línguas, Linguística Aplicada e ensino de línguas. In: Linguagem \& Ensino, v. 7, n. 1, p. 123-156, 2004.

. Narrativas, crenças e experiências de aprender inglês. In: Linguagem \& Ensino, v. 9, n. 2, p. 145-175, 2006.

. Crenças sobre ensino e aprendizagem de línguas: reflexões de uma década de pesquisa no Brasil. In: ALVAREZ, M. L. O.; SILVA, K, A. da (Orgs.). Linguística Aplicada: 
múltiplos olhares. 1. ed. Campinas-São Paulo: Pontes Editores, 2007. p. 27-79.

. Reflexões, crenças e emoções de professores e da formadora de professores. In: BARCELOS, A. M. F.; COELHO, H. S. H. (Orgs.). Emoções, reflexões e (trans) form(ações) de alunos, professores e formadores de professores de línguas. 1. ed. Campinas-SP, 2010. p. 57-81.

BREYER, N. S. Experiências de aprender japonês: dificuldades e crenças de professores em formação. 2010. 77 f. Trabalho de conclusão de curso (graduação em Língua e Literatura Japonesa) - Universidade de Brasília, Brasília, 2010.

CONCEIÇÃO, M. P. Vocabulário e consulta ao dicionário: analisando as relações entre experiências, crenças e ações na aprendizagem de LE. Belo Horizonte-MG, 2004, 287 f. Tese (Doutorado em Linguística Aplicada) - Faculdade de Letras, Universidade de Minas Gerais.

FEIJÓ, F. R. Crenças de alunos brasileiros (de japonês como $\mathrm{LE}$ ) em relação à competência comunicativa em língua japonesa. 2010. 56 f. Trabalho de conclusão de curso (graduação em Língua e Literatura Japonesa) - Universidade de Brasília, Brasília, 2010.

FALTIS, C. Case Study methods in researching language and education. In: HORNBERGER, N.; CORSON, D. (Orgs.). Research methods in language and education. Encyclopedia of Language and Education. v. 8 Dordrecht: Kluwer Academic Publishers, 1997. p. 145-152.

FEIJÓ, F. R.; MUKAI, Y. Crenças de alunos brasileiros (de japonês como LE) em relação à competência comunicativa em língua japonesa: pesquisa piloto. In: CONGRESSO INTERNACIONAL DE ESTUDOS JAPONESES NO BRASIL, 8.; ENCONTRO NACIONAL DE PROFESSORES UNIVERSITÁRIOS DE LÍNGUA, LITERATURA E CULTURA JAPONESA, 21., 2010, Brasília. Anais... Brasília: LET-UnB, 2011. p. 217-224.

FREEBODY, P. Qualitative research in education: interaction and practice. London: Sage, 2003.

FUKUSHI, J. M.; MUKAI, Y. Crenças sobre a habilidade de fala dos aprendizes da língua japonesa como LE (língua estrangeira) em um curso universitário: uma análise da metodologia de ensino. Estudos Japoneses, v. 32, p. 77-100, 2012.

HAYASHI, R. K S. Não existe material ideal, né?: crenças, experiências e ações sobre o material didático de língua japonesa (como LE) na universidade. Brasília, 2015, 250 f. Dissertação (Mestrado em Linguística Aplicada) Departamento de Línguas Estrangeiras e Tradução, Universidade de Brasília, Brasília, 2015. 
HAYASHI, S. Second Language Acquisition Research - Focus on Individual Learners

- Research on the Japanese Language \& the Japanese Language Education, v. 19, 2002.

HORWITZ, E. K. Surveying student beliefs about language learning. In: WENDEN, A. L.; RUBIN, J. (Orgs.). Leaner Strategies in Language Learning. 1. ed. Londres: Prentice-Hall International, 1987. p. 119-129.

ISHIDA, Y. S. As crenças e as motivações sobre a aprendizagem da língua japonesa dos alunos do centro de estudos de línguas (CEL) em São Paulo. 2013. 68 f. Monografia (Especialização em Ensino-aprendizagem de língua japonesa como língua estrangeira) - Universidade de São Paulo, São Paulo, 2013.

KALAJA, P. Student beliefs (or metacognitive knowledge) about SLA reconsidered. International Journal of Applied Linguistics, v. 5, n. 2, p. 191-204, 1995.

KAWAGUCHI, Y; YOKOMIZO, S. Seichô suru kyôshi no tame no nihongo kyôiku guide book (jô) (Guia do ensino da língua japonesa para o crescimento de professores [volume 1]). 1. ed. Tóquio: Hitsuji Shobô, 2005.

LIMA, M. F. de. Um estudo sobre crenças de professores nikkeis: abordagens de ensino em uma escola de colônia. 2015. 191 f. Dissertação (Mestrado em Língua Japonesa) - Universidade de São Paulo, São Paulo, 2015.

MARTINEZ, T. M. As crenças dos alunos sem ascendência japonesa sobre a língua japonesa e suas motivações para estudá-la num centro de estudos de línguas do estado de São Paulo. 2013. 52 f. Monografia (Especialização em Ensinoaprendizagem de língua japonesa como língua estrangeira) - Universidade de São Paulo, São Paulo, 2013.

McKAY, S. L. O professor reflexivo: guia para investigação do comportamento em sala de aula. Trad.: Renata Lea F. Oliveira. 1. ed. São Paulo: Special Books Services Livraria, 2003 (Título original: Teaching listening in the language classroom).

MUKAI, Y. Crenças e necessidades de aprendizes de japonês como LE (língua estrangeira) a respeito da habilidade da escrita e materiais didáticos. Estudos Japoneses, v. 31, p. 193-219, 2011a.

.Nihongo kyôshino tameno biriifu kenkyû:kyôshino seichô wo mezashite(Estudos de crenças para professores de língua japonesa: visando o desenvolvimento dos professores). Brasilia nihongo fukyû kyôkai kyôkaishi (Revista da Associação de Estudos da Língua Japonesa de Brasília), v. 22, p. 45-54, mar. 2011 b.

. JFL nihongo gakushûsha no biriifu kenkyû: nihongo de "kaku (utsu)" koto ni kanshite no yobi kenkyû (Crenças dos aprendizes de japonês como LE: um estudo 
preliminar sobre a habilidade de "escrita (digitada)" em japonês. Brasilia nihongo fukyû kyôkai kyôkaishi (Revista da Associação de Estudos da Língua Japonesa de Brasília), v. 23, p. 34-50, set. 2011c.

. Crenças e necessidades em relação à escrita em japonês: nos casos dos estudantes universitários brasileiros e portugueses. Linguagem \& Ensino, v. 17, n. 2, p. 391 440, 2014.

. Reflexões sobre a cultura de ensinar, cultura de aprender e cultura de sala de aula no contexto multicultural. In: CONGRESSO INTERNACIONAL DE ESTUDOS JAPONESES NO BRASIL, 10; ENCONTRO NACIONAL DE PROFESSORES UNIVERSITÁRIOS DE LÍNGUA, LITERATURA E CULTURA JAPONESA, 23., 2014, Rio de Janeiro. Anais... Rio de Janeiro: Departamento de Letras Orientais e Eslavas, 2014. p. 70-81.

MUKAI, Y.; CONCEIÇÃO, M. P. Aprendendo língua japonesa: crenças, ações e reflexões de uma aluna brasileira de japonês como língua estrangeira. In: MUKAI, Y.; JOKO, A. T.; PEREIRA, F. P. (Orgs.). A Língua Japonesa no Brasil: reflexões e experiências de ensino e aprendizagem. 1. ed. Campinas-SP: Pontes Editores, 2012. p. 111-154.

MUKAI, Y.; ÖZERHAN, T. Beliefs of JFL learners on Japanese writing skills - A case study of JFL learners of Istanbul Bilgi University and University of Brasilia -. In: JAPANESE TEACHERS' MEETING OF TURKEY, 10., 2011, Istambul. Anais... Istambul: 2011. p. 58-70.

NASCIMENTO, E. T. do. O professor de língua japonesa (LE): crenças e ações de três professores universitários com trajetórias diferenciadas de aquisição/ aprendizagem (LM, LH e LE). 2013. 186 f. Dissertação (Mestrado em Linguística Aplicada) - Universidade de Brasília, Brasília, 2013.

OLIVEIRA, A. W. M. de. É assim que eu escrevo: estratégias de aprendizagem de kanji e crenças de professores de língua japonesa em formação. 2013. 163 f. Dissertação (Mestrado em Linguística Aplicada) - Universidade de Brasília, Brasília, 2013.

OSHIRO, E. N. As crenças de uma aluna nikkei em relação ao aprendizado de língua japonesa como língua estrangeira: estudo de caso. 2013. 56 f. Monografia (Especialização em Ensino-aprendizagem de língua japonesa como língua estrangeira) - Universidade de São Paulo, São Paulo, 2013.

PAJARES, M. F. Teachers' beliefs and educational research: cleaning up a messy construct. Review of Educational Research, v. 62, n. 3, p. 307-332, 1992 (fall).

RODRIGUES, C. A abordagem processual no estudo da tradução: uma meta-análise qualitativa. Cadernos de tradução, v. 2, n. 10, p. 23-57, 2002. 
SATÔ, I. Shitsuteki deeta bunsekihô (Método de análise para dados qualitativos). 1. ed. Tóquio: Shinyôsha, 2008.

SILVA, K. A. da. (Org.). Crenças, discursos \& linguagem - volume 1. 1. ed. CampinasSão Paulo: Pontes editores, 2010.

TUDOR, I. Learner-centredness as Language Education. 1. ed. Cambridge: Cambridge University Press, 1996.

UMETSU, R. K. G. As influências das crenças dos alunos acerca do corpo docente em relação à aprendizagem de japonês como LE: estudo de caso. 2013. $49 \mathrm{f}$. Trabalho de conclusão de curso (graduação em Língua e Literatura Japonesa) Universidade de Brasília, Brasília, 2013.

WENDEN, A. L. An introduction to metacognitive knowledge and beliefs in language learning: beyond the basics. System, v. 27, p. 435-441, 1999.

WOODS, D. The social construction of beliefs in the language classroom. In: KALAJA. P.; BARCELOS, A. M. F. (Orgs.). Beliefs about SLA: New Research Approaches. Dordrecht: Kluwer, 2003. p. 201-229.

YOKOMIZO, S. Nihongo kyôshi no tameno action research (Pesquisa-ação para professores da língua japonesa). 1. ed. Tóquio: Bonjinsha, 2000. 